\title{
The utilisation of risk-based frameworks for managing healthcare waste: a case study of the National Health Service in London
}

\author{
Alex Akpieyi ${ }^{\mathrm{a}}$, Terry L. Tudor ${ }^{\mathrm{b} 1}$, Cleber Dutra $^{\mathrm{c}}$ \\ ${ }^{\mathrm{a}}$ Faculty of Health and Medical Science. University of Surrey. Guildford. Surrey:UK. GU2 \\ 7WG \\ ${ }^{b}$ School of Science and Technology. University of Northampton. Northampton:UK. NN2 6JD \\ ${ }^{\mathrm{c}}$ Department of Management. Universidade de Fortaleza (UNIFOR). Fortaleza. Ceará:Brazil.
}

\begin{abstract}
The management of waste from healthcare facilities can potentially pose a significant risk. In the UK, there are a number of increasingly stringent pieces of legislation and policies to mitigate against these risks. Using the taxonomy of organisational change (Vuuren, 1998), this study evaluated the inherent risks within the reported practices and policies of 21 Acute Care Trusts within the National Health Service (NHS) in London, England. The most frequently occurring exposures involved contact with sharps, infectious agents and hazardous substances and personal injuries during waste handling. Most of the reported exposures occurred within the wards and for this location, highly significant correlations were found between nurses and contact with sharps. The implications of these findings for risk management are also discussed.
\end{abstract}

Key words: Vuuren Taxonomy, Healthcare waste, Medical waste, Health and Safety, Risk management

1 Correspondence address. Terry Tudor. School of Science and Technology, University of Northampton. Northampton. NN2 6JD. Tel: 01604 893372; Fax: 01604 893071; Email: terry.tudor@northampton.ac.uk 


\section{Introduction}

The effective management of the infectious (clinical) fraction of healthcare waste (HCW) in the UK has increasingly gained attention over the last two decades, due to the need for compliance with increasingly stringent legislation and policies (Townend et al., 2009; Tudor et al., 2010; DH, 2011). HCW are the by-products of healthcare activities, comprised of: sharps, non-sharps, blood, human tissue, chemicals, pharmaceuticals, medical devices and radioactive materials (WHO, 2007). Clinical wastes are defined in the UK, in the Controlled Waste (England and Wales) Regulations 2012, as:

- Any waste which consists wholly or partly of human or animal tissue, blood or body fluids, excretions, drugs or other pharmaceutical products, swabs or dressings or syringes, needles or other sharp instruments, being waste which unless rendered safe may prove hazardous (including microbial (infectious, pharmacological and/or physical (e.g. sharps) dangers to any person coming into contact with it

- Any other waste arising from medical, nursing, dental, veterinary, pharmaceutical or similar practice, investigation, treatment, care, teaching or research, or the collection of blood for transfusion being waste, which may cause infection to any person coming into contact with it

The management of clinical waste can present significant physical, chemical and microbiological risks to those involved in the handling, treatment and disposal processes (Salkin, 2004; HPA, 2008; HSE, 2011a). Indeed, sharps accounted for some $68 \%$ of all percutaneous injuries (HPA, 2008). However, while there has been much 
work undertaken on clinical staff, there has been limited empirical research of ancillary staff (HSE, 2011a). Using a case study approach of the 21 Acute Care Trusts within the National Health Service (NHS) in London, England, this study aimed to examine the use of selected risk management tools for the management of waste from healthcare facilities.

\subsection{The NHS}

The NHS is one of the largest organisations in the world, employing approximately 1.7 million people, over half of whom are directly involved in healthcare service provision (NHS, 2014). The average number of days lost per worker due to injuries and illnesses in the health and social sector is amongst the highest across all sectors at 1.78, compared to an average of 0.98 (HSE, 2013a). This translates into lost-time of approximately $£ 1$ billion per annum (HSE, 2010). At the time of the study, the healthcare services in London employed a workforce of over 200,000 employees (NHS, 2008).

\section{Risk management}

Of the 156,000 incidents reported between 2004 and 2005 under the Reporting of Injuries, Diseases and Dangerous Occurrences Regulations 1995 (RIDDOR), only 61 fell into the 'reportable incidents' category. This figure, however, does not reflect the 'numerous' minor sharps injuries that occurred in the healthcare sector, which were either considered low risk or resulted in less than three days lost time (HSE, 2011b). In managing $\mathrm{HCW}$, emphasis is placed on managing the intrinsic risks that $\mathrm{HCW}$ poses to the environment and the persons frequently exposed (DH, 2011). Studies 
suggest that systems for managing the associated health and safety risks may be inadequate (HPA, 2008; HSE, 2011a; HM Treasury, 2013).

In high-risk industries (e.g. chemical, nuclear and oil exploration), predictive tools and models have for some time been used to proactively manage risks, through for example hazard mapping (Reniers et al., 2005; Kennedy and Kirwan, 1998; Vuuren, 1999).

The OSH Framework Directive (1989), is the key EU Directive covering health and safety (EU, 2013). In addition, there are a number of individual directives which define how to assess risks and, in some instances set limit values for certain substances or agents. A series of EU directives based on Article 114 of the Treaty on the Functioning of the European Union (ex Article 95 TEC) also relate to safety and health (EASHW, 2013).

Implementation of the directives in the UK is through the Control of Major Accidents Hazards (COMAH) Regulations 1999. These regulations prescribe the principle of risk elimination and reduction to levels as low as reasonably practicable (ALARP) (HSE, 1999). Specifically related to sharps waste are the Health and Safety (Sharps Instruments in Healthcare) Regulations 2013 (HSE, 2013b).

\subsection{Risk management tools}

A taxonomy of organisational failure applied to clinical risk management found that the majority of the patient-safety incidents $(45 \%)$ were caused by organisational and 
management failures, while human factors, relating to incorrectly carrying out tasks, followed closely (Vuuren, 1999).

Over the years, a variety of qualitative, quantitative, deterministic and probabilistic risk analysis techniques have been developed (Khan and Abbasi, 1998; Tixier et al., 2002; Vaurio, 2010). The most common of these include (Khan and Abbasi, 1998; Tixier et al., 2002): Hazard and Operability Study (HAZOP); Failure Mode and Effect Analysis (FMEA); and Bow-Tie Analysis (BTA). The techniques are all aimed at forecasting and analysing the consequences of likely accidents, and emergency preparedness. FMEA and FTA have been applied in clinical settings as a means of achieving clinical governance in the area of error reduction, and improving patient safety (Paparella, 2007; Cagliano et al., 2011; Chiozza and Ponzetti, 2009). According to Paparella (2007), the use of FMEA allows for a proactive assessment of what things could go wrong in a system, and provides an opportunity to rectify the weak links before failures occur. FMEA and ETA are increasingly being considered outside of their traditional environments, including waste management (Pollard et al., 2006). FMEA is a particularly appropriate technique for managing the hazards of $\mathrm{HCW}$, due to its underpinning in the proactive, rather than reactive assessment of the risks (Cagliano et al., 2011).

\section{Methods}

Between June - August 2011 incidences of patient safety and HCW-related risks were obtained through Freedom of Information (FOI) requests submitted to the Health and Safety Executive (HSE), the Department of Health (DH), the National Patient Safety 
Advisory (NPSA), the HPA, and each of the 21 NHS Trusts. The effective response rate obtained was approximately $33 \%$.

The relevant types of data were established based on the taxonomy of organisational failure (Vuuren, 1999). However, the research utilised the historical data on patient safety-related risks to develop a failure taxonomy, which was thereafter tested against the data on the HCW-related risks.

\subsection{Incidences of Patient-Safety Related Risks}

In July 2011, FOI requests were sent to the DH and NSPA regarding incidences of medical error reported, for the period January 2009 to December 2009.

\subsection{Incidences of HCW-Related Risks}

In July 2011, FOI requests were sent to the DH, HSE, HPA, and each of the 21 NHS Acute Trusts regarding incidences of health and safety risks from HCW for the period January 2005 to December 2009.

\subsection{Review of Trust' Health and Safety Policies}

The evaluation criteria for the review of the Health and Safety policies for each of the Trusts were based on (Pollard et al., 2006). To ensure consistency, the focus areas identified from each policy review was carried over to the next, and any new areas noted and included for subsequent reviews. Also, as the means of implementation was often not precisely stated, a list of the four most commonly observed implementation methods was subsequently employed. 


\subsection{Data Analyses}

The data were analysed using the Predictive Analysis Software (PASW) Statistics application using a range of descriptive and bivariate analyses. In categorising data, it is important to first identify the recurring regularities in the data and then decide what elements fit together (Patton, 2002). Therefore the analyses sought to determine and establish the relevant categories. This involved creating common themes by assigning codes to the various data elements, and grouping data sets to form themes. The thematic analysis of the incidences data was guided primarily by the questions that the FOI requests sought to answer (Stake, 1995). This approach resulted in the identification of four data categories: Incident types; Incident severity; Staff category; and Root causes.

To identify patterns and trends, a coding scheme was developed, by assigning alpha numeric values to individual data elements, for use in reviewing the health and safety policies. This content analysis enabled the documents to be broken down into discreet parts for contextual examination in relation to the predefined, coded evaluation criterion.

Triangulation was achieved by comparing and cross-checking the consistency of the analysed information on the incidences of HCW-related risks with that of the health and safety policies, based on (Patton, 2002). The results were generalised using analytic generalisation, rather than statistical analyses to establish a pattern-model theory between incidents and causes (Marschan-Piekkari and Welch, 2004). This comparison served to validate the applicability of the patient safety risk management 
techniques in a HCW management context, on the basis of common classifications of causes of failures.

\section{Results}

Table 1 illustrates that there was a statistically significant relationship between Trust type and four key factors, namely: (1) contact with sharps $(65.57, P<0.001)$; (2) infectious agents (58.69, $P<0.001)$; (3) manual handling (51.09, $P<0.001$ ); and (4) being struck by or against an object (55.34, $P<0.001)$.

Table 1: The association between Trusts and exposure categories

\begin{tabular}{|l|c|c|c|}
\hline $\begin{array}{l}\text { Categories of } \\
\text { Exposure }\end{array}$ & $\begin{array}{c}\text { Pearson } \\
\text { Chi Square } \\
\text { Value }\end{array}$ & Df & $\begin{array}{c}\text { Asymp. Sig } \\
\text { (2-sided) }\end{array}$ \\
\hline Contact (Sharps) & 65.57 & 6 & 0.000 \\
\hline Contact (Infectious) & 58.69 & 6 & 0.000 \\
\hline Personal Injury & 16.58 & 6 & 0.011 \\
\hline Contact (Hazardous) & 15.40 & 6 & 0.017 \\
\hline Manual Handling & 51.06 & 6 & 0.000 \\
\hline Struck (Against or By) & 55.34 & 6 & 0.000 \\
\hline Slips, Trips \& Falls & 19.46 & 6 & 0.003 \\
\hline
\end{tabular}

\subsection{Occupational Health and Safety Incidents}

There were seven key categories of health and safety hazards, comprised of contact with sharps (73.5\%), contact with infectious agents (16.3\%), personal injury (3\%), contact with hazardous materials and manual handling (3\% each), struck by an object (1\%), and slip, trips and falls $(0.2 \%)$. 
Some $73.5 \%(225 / 306)$ of the occupational health and safety incidents relating to HCW resulted from contact with sharps, while $16.3 \%$ (50/306) were from contact with infectious agents. The remaining 10.2\% (31/306) incidents collectively consisted of contact with hazardous materials, manual handling, and other hazards that resulted in ill-health and physical type injuries. Some 33\% (101/306) of the incidents reported for the period originated from T6, followed by $31.7 \%$ (97/306) from T7, with the lowest incidence reported by $\mathrm{T} 12$, constituting just $2.6 \%(8 / 306)$.

\section{2: Incident Types and Points of Occurrence}

The majority of incidents occurred within the hospital wards, accounting for $67.4 \%$ $(198 / 306)$ of the total. Approximately $76.5 \%$ (150/198) of these cases were through contact with sharps alone. The operating theatre and the Accident \& Emergency (A\&E) departments recorded 9.8\% (30/306) and 8.8\% (27/306) respectively, with exposure to sharps accounting for 30 incidents in total for both locations. There were only $1.3 \%$ (4/306) incidents recorded in non-clinical facilities within the hospitals and only $50 \%(2 / 4)$ of these were as a result of contact with sharps, while the other $50 \%$ involved manual handling. Figure 1 illustrates the nature of the relationships between department type and the type of exposure. Highly significant and strong positive relationships were observed between: wards and contact with sharps $(r=0.997, P$ $<0.001)$; A\&E/theatre and contact with hazardous agents $(r=0.897, P=0.006 / r=$ $0.783, P=0.037$ respectively $) ;$ A\&E/theatre and personal injury $(r=0.828, P=$ $0.022 / r=0.932, P=0.002$ respectively); and theatre and contact with infectious materials $(r=0.842, P=0.017)$. 


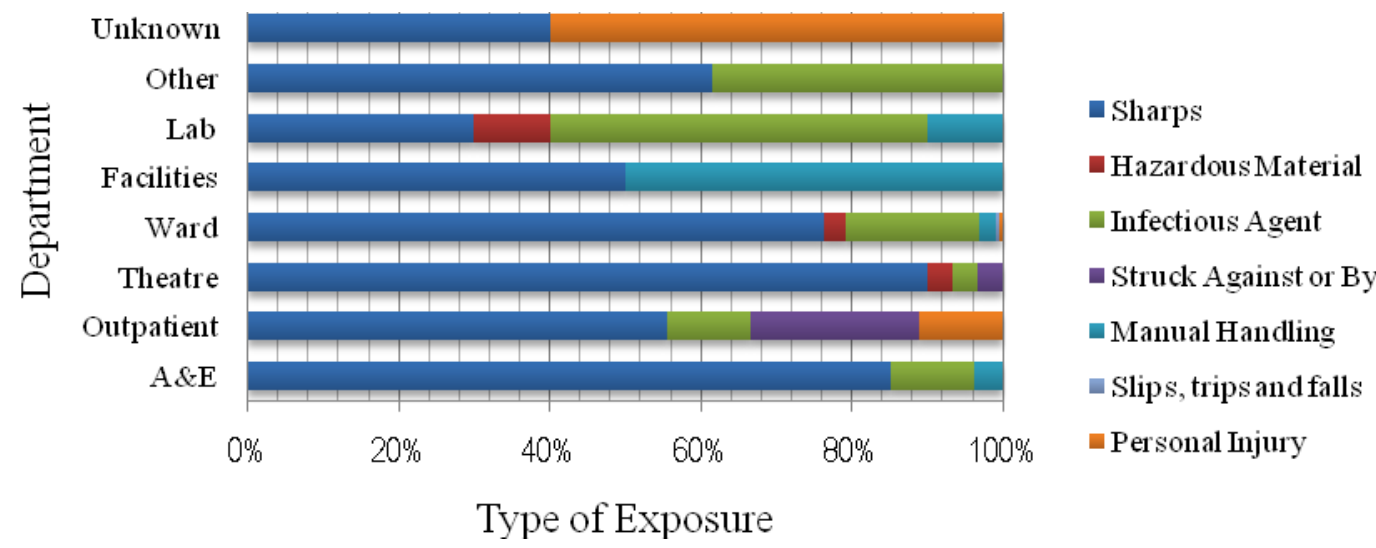

Figure 1: Incident types and locations of occurrence

\section{3: Patterns of Exposure}

The main occupational groups observed to be at risk of exposure included: nurses; doctors; and other healthcare professional such as midwives, auxiliary staff and laboratory personnel (Figure 2). Information on the occupational groups involved in $47.1 \%(144 / 306)$ of the incidents was unavailable and these were categorised as unknown. The largest identifiable occupational group exposed to incidents were the nurses, constituting $31.4 \%$ (96/306), followed by cleaners at $7.5 \%(23 / 306)$, while other auxiliary personnel comprised $6.2 \%(19 / 306)$ of the total. There was a statistically significant and positive correlation between nurses and wards $(r=0.791$, $P=0.034)$ 


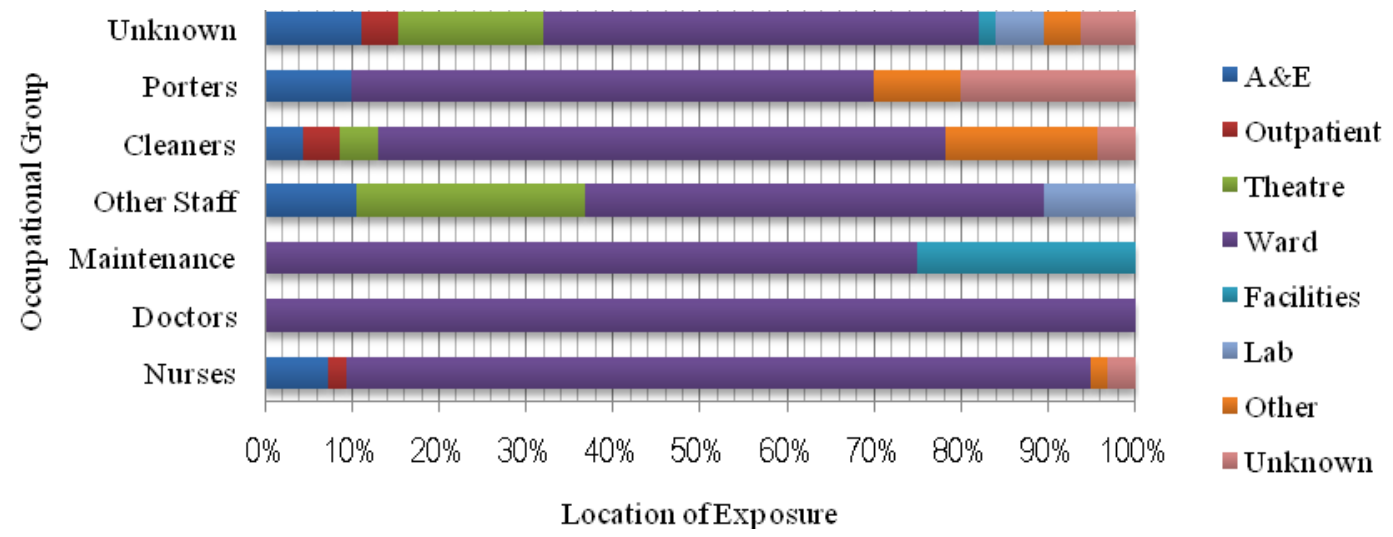

Figure 2: Exposure location and occupational groups

Figure 3 illustrates that there were significant correlations between nursing staff and contact with sharps $(r=0.832, P=0.020)$. There were also significant incidents of slips, trips and falls for maintenance staff $(r=0.944, P=0.001)$.

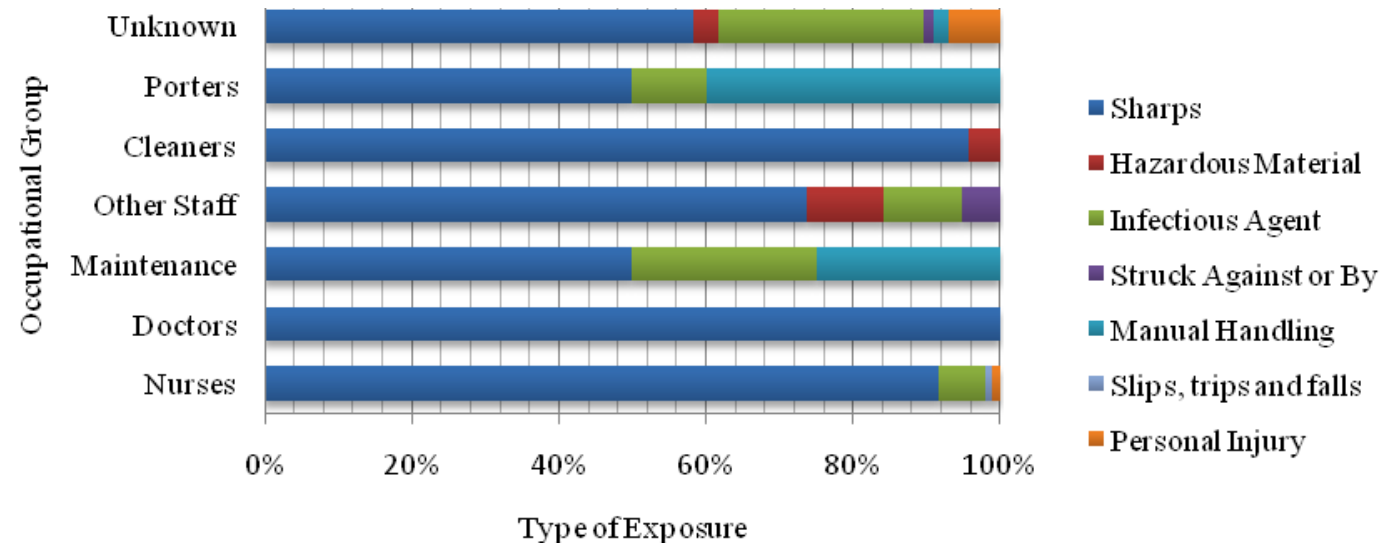

Figure 3: Exposure types and occupational groups

\section{4: Patterns of Harm}

The severity of lost-time was classified into four main categories, comprising: None; 1-3 days; $>3$ days; and, Unknown (where the data were insufficient to establish the 
appropriate lost-time severity category). The majority of exposures $(69.3 \% ; 212 / 306)$ resulted in no time-off from work, even though $72.2 \%(153 / 306)$ of these involved contact with sharps. The exposures that resulted in 1-3 days away from work constituted $18.6 \%(57 / 306)$, while those necessitating more than 3 days off amounted to only $1 \%(3 / 306)$. Insufficient data led to classifying the lost-time for $11.1 \%$ (34/360) of exposures, as unknown. Some $66.3 \%$ (203/306) of all exposures were considered 'minor', while 25.2\% (77/306) resulted in no harm. Moderate harm constituted 5.9\% (18/306), while major and extreme exposures were collectively $1 \%$ (3/306). The degree of harm for $1.6 \%$ (5/306) of the exposures was unknown.

Approximately $25 \%$ of the exposures were classified as near-misses, resulting in no harm to the persons involved, with the vast majority of these occurring within the wards. Only one of the $306(0.3 \%)$ was considered extreme although the exact nature of the exposure could not be established from the data. Insufficient data also saw the classification of five exposures within the wards into the 'unknown degree of harm' category.

\section{5: Causative Patterns}

Non-compliance was the highest cause of incidences with $51 \%$ of all exposures. Some $90.4 \%$ of non-compliances were attributed to contact with sharps. Failure to use PPE occurred in only $2.3 \%(7 / 306)$ of the cases, while human error was blamed for $25.5 \%$.

\section{6: Analysis of the Trusts' Health and Safety Policies}

Only five Trusts (T6, T7, T9, T11 and T12), constituting 71.4\% of the sample, had approved health and safety policies. The remaining 28.6\% (T8 and T10) either had 
none or were in the process of developing one. The policies were evaluated against a five-point criterion prescribed for the design and implementation of a health and safety policy (HSE, 2011a). Some 16 key areas of policy focus were cumulatively identified from the review of all the health and safety policy documents. These focus areas included: fire safety; hazardous substances; manual handling; infection control; equipment safety, radiation protection; working with display screens; workplace violence; slips, trips and falls; facility security; traffic management; contractor control; falling objects; lone work; terrorism; and, waste management. Only one of the seven Trusts (T7), specifically considered waste management within the scope of its health and safety policy. No statistically significant correlations were observed between the number of years of policy implementation (maturity continuum), the number of policy focus areas, and the number of HCW-related exposures $(r=0.535, P$ $=0.216$ and $r=0.176, P=0.705$, respectively). Similarly, no significant link was found regarding the availability of health and safety policies and the number of HCWrelated exposures. The significantly higher rank sums of the Trusts without health and safety policies indicated that policy availability did not have a strong effect on the frequency of exposures.

Based on Vuuren (1999), the classification of exposure causes yielded 241 organisational failure causes, comprised of attitudes to safety $(67 \% ; 163 / 241)$ and skills and knowledge (33\%; 78/241).

\section{Discussion}




\subsection{Occupational Exposure Patterns}

The most frequently occurring exposures involved contact with sharps and with infectious agents, and personal injuries during waste handling. Contact with sharps constituted approximately $73 \%$ of the reported exposures within the study population. This corresponded well with the findings of the HPA (2008), which noted that $76 \%$ of all related exposures between 2000 and 2007 involved percutaneous injuries. Salkin (2004) also found exposure to sharps to be the most frequently occurring risk from HCW. Even though slips, trips and falls were found to constitute less than $1 \%$ of incidents reported in this study, these factors are still a major cause for concern in the NHS, with respect to employee lost-time (HSE, 2011b). It is, however, noted that in the context of HCW management, slips, trips and falls did not feature as often as other forms of exposure.

Approximately $65 \%$ of the reported exposures occurred within the wards and for this location, highly significant correlations were found between nurses (the occupational group most at risk of exposure) and contact with sharps. Although a significant number of the incident reports reviewed were lacking in the necessary details to establish the occupational groups involved, the fact that over half of these exposures occurred within the wards suggests they may likely have involved contact with sharps by nurses as well. The nursing profession has long been associated with the highest risks of exposure from HCW (HPA, 2008). The findings from the present study also suggest that cleaners and porters collectively account for approximately $11 \%$ of all exposures reported, which reflected a higher proportion than was observed previously (HPA, 2008). Without actual site visits, it was impossible to relate to the findings to practice. However, in this study, only $1.3 \%$ of exposures were reported to have 
occurred around the general facilities, and these involved contact with sharps and manual handling.

Despite the high frequency of contact with sharps, most exposures were noted to have caused no harm or just minor harm. Strong correlations were observed between contact with sharps and no lost time from work. It is impossible to state precisely what factors may have been responsible for these incidents, although the standard practice of vaccinating workers in similar environments against common blood-borne infections like hepatitis and tetanus could be a contributory factor (HSE, 2010). Exposure to infectious agents also registered as a concern worthy of note, because most of these exposures took the form of contact with sharps and inconsistencies in incident reporting made it difficult to exclude one exposure from the other. Nevertheless, the root cause of a vast majority of exposures to sharps and other infectious materials, involving frontline and ancillary staff, is a failure in the safe disposal of HCW by healthcare professionals. This study found that over $90 \%$ of all exposures resulted from failures to follow the Department of Health guidance 'Safe Management of Healthcare Waste' (DH, 2011), and were thus classifiable as being caused by non-compliance. Furthermore, about $25 \%$ of all exposures were reported as resulting in no harm, of which less than $2 \%$ of these lacked necessary details, indicating that higher exposure numbers could have been recorded. The featuring of these 'no harm incidents', however, suggests that opportunities exist for the incorrect practices to be corrected through near miss reporting. Regarding the causes of exposures, human error was the second most significant cause, occasioned by postprocedure contact with sharps, perhaps in the course of recapping needles or as a consequence of non-compliance with the universal precautions. Indeed, NHS (2006) 
stated that exposures, which occurred post-clinical procedure, but prior to disposal, accounted for approximately $50 \%$ of all needle-stick injuries either through collisions, during clearing up or whilst recapping.

\subsection{Health and Safety Management Programmes}

As evidenced by the health and safety policy documents reviewed, over $70 \%$ of the Trusts sampled had approved policies. Only one had none, while another was unable to provide its, as the document was said to be undergoing review. Policy review is a salient aspect of health and safety management (HSE, 2011a), which could perhaps explain why this was the case with that Trust. However, it was noted as unusual that a Trust had no health and safety policy document, as this clearly translated into a breach of duty imposed under the Health and Safety at Work, etc. Act, 1974 s.2(3), which requires all employers of more than five persons to maintain health and safety policies. However, it was interesting to note that the Trust without a health and safety policy accounted for only $5 \%$ of the total exposures reported during the study, which suggests that there was perhaps no correlation between having a health and safety policy document and the frequency of exposures reported. Inversely, the Trust whose policy was undergoing review accounted for $16.3 \%$ of the total exposures.

There were some significant, though weak correlations between the number of years Trusts' health and safety policies had been in place and the number of exposures reported. Exposure rates decreased as the length of time the policies had been in place increased (i.e. there was an inverse relationship). It was interesting to note, that all the Trusts with health and safety policies, had clearly defined roles and responsibilities for key Trust personnel who would implement the policies. Policy implementation 
strategies were also observed to vary, as did the focus areas and frequencies of exposure. In keeping with the minimum prescribed occupational health and safety service standard for the NHS (DH, 2001), all policies reviewed indicated that at least a safe system of work (consisting primarily of risk assessment and control), was implemented in combination with operating procedures in over $40 \%$ of the Trusts sampled. Ironically, those with the highest and lowest reported exposures were both observed to be implementing comprehensive occupational health and safety management systems. Similarly, of all those with policies, these two were also found to have the fewest number of policy focus areas, ranging between six and 10, as ranked on the interval scale. It must be emphasised at this point that the style or proficiency of occupational health and safety management, as expressed by a policy document, may not accurately reflect the actual practices, standards or organisational culture in practice.

\subsection{Organisational Culture (Safety Attitudes)}

Almost all exposures involving contact with sharps, occurred as a result of a failure of the responsible person(s) to appropriately dispose of needles or instruments following clinical procedures. According to Salkin (2004), occupational exposures, which occurred after the procedure, are largely preventable through adequate compliance with the procedures for the safe handling and disposal of sharps and other HCW materials.

\subsection{Organisational Structure (Skills and Knowledge)}

With regards to human error, the review of exposure report descriptions revealed a high incidence of exposures resulting from accidental contact with waste materials 
due to distractions or wrongful judgement on the part of the healthcare worker. These findings, in the course of reviewing the Trusts' exposure data were consistent with (HPA, 2008). An inherent problem in HCW management, as noted by Muhlich et al. (2003), is that of training staff such that there is no confusion when tasked with handling waste, to the extent of compromising occupational health and safety for themselves or others. Phillips (1999) stated that in practice, instructing diverse groups of hospital workers, involved in HCW management, of their responsibilities and safe practices often presented numerous challenges. The level of human error observed during this study could be attributed to similar challenges encountered by the Trusts sampled.

\subsection{The Applicability of the Taxonomy}

The efficacy of using risk management tools to proactively manage safety critical operations, and for analysing the interrelationships between causative factors, has been demonstrated by various studies (Kennedy and Kirwan, Vuuren, 1999; Paparella, 2007).

Theoretically derived error taxonomies are more likely to be generic in applicability (Taib et al., 2011). With more in-depth information regarding the incidences of the exposures, the organisational root causes of failures could be further and more explicitly classified across the nine factors of the Vurren (1999) taxonomy. By considering the organisational and systemic perspectives of failures, the most critical aspects of a system can thus be identified (Stake, 1995). In a similar context, Cosby (2003) identifies teamwork failure as the major contributing factor in the majority of serious untoward events concerning clinical governance, and a focus area for risk management. Kennedy and Kirwan (1998) also found common ground with previous 
researchers in the prioritisation of the sub-elements of the organisation (safety culture and safety management), for the detailed modelling of adverse events, in determining appropriate mitigation strategies.

\section{Conclusion}

Using 21 Acute Care NHS Trusts from London, as the case study, this study found that the most frequently occurring exposures involved contact with sharps, infectious agents and hazardous substances and personal injuries during waste handling. Most of these occurred within the wards, primarily involving nurses and contact with sharps. It is equally important to note the high percentage of 'unknown' HCW exposure causes that were excluded from the test in this study, which, with additional information, could have reflected an entirely different spread across the nine factors, and perhaps revealed details that may have necessitated the creation of some domain-specific organisational failure factors. In general, adverse events occur due to a combination of factors, of which those relating to the organisation were crucial, as they can significantly influence failure dynamics. The strategy for risk management varies according to the dynamics of underlying influences. Consequently, similarities in the causal factors of disparate events would suggest that comparable approaches to management may be adopted. Thus it can be argued that similarly to its application in other contexts (e.g. Paparella, 2007; Cagliano et al., 2011), risk analysis tools such as FMEA, Healthcare Failure Mode Effect Analysis (HFMEA) and Clinical Risk Effect Analysis (CREA), can be successfully employed to mitigate against the health and safety risks associated with the management of $\mathrm{HCW}$. 


\section{References}

Cagliano, A.C., Grimaldi. S., Rafele. C., 2011. A systematic methodology for risk management in healthcare sector. Safety Science 49, 5, 695-708.

Chiozza, M.L., Ponzetti, C., 2009. A model for reducing medical errors. Clinica Chimica Acta 404, 1, 75-78.

Cosby, K.S., 2003. A framework for classifying factors that contribute to error in the emergency department. Annals of Emergency Medicine 42, 6, 815-823.

DH (Department of Health) 2001. The effective management of occupational health and safety services in the NHS. HMSO, London, England.

DH (Department of Health) 2011. Safe management of healthcare waste. (2nd ed.) HMSO, London.

EASHW (European Agency for Safety and Health at Work) 2013. European directives. Available at: https://osha.europa.eu/en/legislation/directives accessed on $\underline{28 / 10 / 2013}$

EU (European Union) 2013. The European Framework Directive on Safety and Health at Work (Directive 89/391 EEC). Brussels. 
HM Treasury 2013. Orange book: management of risk - principles and concepts," HMSO. London. England.

HPA (Health Protection Agency) 2008. Eye of the Needle - United Kingdom surveillance of significant occupational exposures to bloodborne viruses in healthcare workers. London, UK.

HSE (Health and Safety Executive) 2013a. Labour Force survey 2011/12. Available at: http://www.hse.gov.uk/statistics/lfs/index.htm Accessed on 28/10/2013

HSE (Health and Safety Executive) 2013b. Health and Safety (Sharps Instruments in Healthcare) Regulations 2013. HMSO. London. England.

HSE (Health and Safety Executive) 2011a. Health and safety made simple: The basics for your business. HSE Books, London, England.

HSE (Health and Safety Executive) 2011b. Needle-stick injuries. Available from: http://www.hse.gov.uk/healthservices/needlesticks/ Accessed 11 June 2011.

HSE (Health and Safety Executive) 2010. Health and safety in health and social care services. Available from: http://www.hse.gov.uk/healthservices/ Accessed 25 February 2011. 
HSE (Health and Safety Executive) 1999. Control of major accident hazards Regulations 1999 (COMAH). Available from:

http://www.hse.gov.uk/comah/background/comah99.htm Accessed 23 July 2011.

Kennedy, R., Kirwan, B., 1998. Development of a hazard and operability-based method for identifying safety management vulnerabilities in high risk systems. Safety Science 30, 3, 249-274.

Khan, F., Abbasi, S.A., 1998. Techniques and methodologies for risk analysis in chemical process industries. Journal of Loss Prevention in the Process Industries 11, $4,261-277$.

Marschan-Piekkari, R., Welch, C., 2004. Handbook of qualitative research methods for international business. Edward Elgar, Cheltenham, England.

Muhlich, M., Scherrer, M., Daschner, F.D., 2003. Comparison of infection waste management in European hospitals. Journal of Hospital Infection 55, 4, 260-268.

NHS (National Health Service) Scotland 2006. Needlestick injuries: sharpen your awareness. Available from:

http:/www.scotland.gov.uk/Publications/2001/05/9203/File-1 Accessed 15 August 2011. 
NHS (National Health Service) London 2008. NHS London strategic plan. Available from: http://www.london.nhs.uk/publications/corporate-publications/nhs-londonstrategic-plan Accessed 1 July 2011.

NHS (National Health Service) 2014. About the NHS. National Health Service, UK Available from: http://www.nhs.uk/NHSEngland/thenhs/about/Pages/overview.aspx Accessed 17 January 2014.

Paparella, S., 2007. Failure mode and effects analysis: a useful tool for risk identification and injury prevention. Journal of Emergency Nursing 33, 4, 367-371.

Patton, M.Q., 2002. Qualitative research and evaluation methods. (3rd ed.) Sage Publications, London, England.

Phillips, G., 1999. Microbiological aspects of clinical waste. Journal of Hospital Infection 41, 1, 1-6.

Pollard, S.J.T., Smith, R., Longhurst, P.H. et al., 2006. Recent development in the application of risk analysis to waste technologies. Environment International 32, 8, 1010-1020.

Reniers, G.L.L., Dullaert, W., Ale, B.J.M., et al., 2005. The use of current analysis tools evaluated toward preventing external domino accidents. Journal of Loss Prevention in the Process Industries 18, 3, 119-126. 
Salkin, I.F., 2004. Review of health impacts from microbiological hazards in healthcare wastes. World Health Organization (WHO), Geneva.

Stake, R., 1995. The art of case research. Sage Publications, London, England.

Taib, I.A., McIntosh, A.S., Caponecchia, C. et al., 2011. A review of medical error taxonomies: A human factors perspective. Safety Science 49, 5, 607-615.

Tixier, J., Dusserre, G., Salvi, O., et al., 2002. A review of 62 risk analysis methodologies of industrial plants. Journal of Loss Prevention in the Process Industries 15, 4, 291-303.

Townend, W., Cheeseman, C, Edgar J, et al., 2009. Factors driving the development of healthcare waste in the United Kingdom over the past 60 years. Waste Management \& Research 27, 4, 362-373.

Tudor, T.L., Woolridge, A.C., Phillips, C.A., et al., 2010. Evaluating the link between the management of clinical waste in the National Health Service (NHS) and the risk of the spread of infections: a case study of three hospitals in England. International Journal of Hygiene and Environmental Health 213, 6, 432- 436.

Vaurio, J.K., 2010. Ideas and development in importance measures and fault-tree technologies for reliability and risk analysis. Reliability Engineering and System Safety 95, 2, $99-107$. 
Vuuren, W., 1999. Organisational failure: lessons from industry applied in the medical domain. Safety Science 33, 1-2, 13-29.

WHO (World Health Organisation) 2007. Factsheet No. 253 - Waste from healthcare activities. Geneva. Switzerland. 